\title{
Stereotactic laser ablation as treatment for brain metastases that recur after stereotactic radiosurgery: a multiinstitutional experience
}

\author{
*Mir Amaan Ali, BS, ${ }^{1}$ Kate T. Carroll, BA, ${ }^{1}$ Robert C. Rennert, MD, ${ }^{1}$ Thomas Hamelin, DNP, ${ }^{2}$ \\ Leon Chang, MD, ${ }^{3}$ Brian P. Lemkuil, MD, ${ }^{3}$ Mayur Sharma, MD, ${ }^{4}$ Jill S. Barnholtz-Sloan, PhD, ${ }^{5}$ \\ Charlotte Myers, CNRN, MS, ANP-C, ${ }^{6}$ Gene H. Barnett, MD, ${ }^{4}$ Kris Smith, MD, ${ }^{6}$ \\ Alireza M. Mohammadi, MD, ${ }^{4}$ Andrew E. Sloan, MD, ${ }^{5}$ and Clark C. Chen, MD, PhD ${ }^{1}$
}

Departments of ${ }^{1}$ Neurosurgery, ${ }^{2}$ Radiology, and ${ }^{3}$ Anesthesia, University of California, San Diego, California; ${ }^{4}$ Department of Neurosurgery, The Rose Ella Burkhardt Brain Tumor and Neuro-Oncology Center, and ${ }^{5}$ Department of Neurosurgery, University Hospitals, Cleveland, Ohio; and ${ }^{6}$ Department of Neurosurgery, Barrow Neurological Institute, Phoenix, Arizona

OBJECTIVE Therapeutic options for brain metastases (BMs) that recur after stereotactic radiosurgery (SRS) remain limited.

METHODS The authors provide the collective experience of 4 institutions where treatment of BMs that recurred after SRS was performed with stereotactic laser ablation (SLA).

RESULTS Twenty-six BMs (in 23 patients) that recurred after SRS were treated with SLA (2 patients each underwent 2 SLAs for separate lesions, and a third underwent 2 serial SLAs for discrete BMs). Histological findings in the BMs treated included the following: breast $(n=6)$; lung $(n=6)$; melanoma $(n=5)$; colon $(n=2)$; ovarian $(n=1)$; bladder $(n$ $=1$ ); esophageal $(n=1)$; and sarcoma $(n=1)$. With a median follow-up duration of 141 days (range 64-794 days), 9 of the SLA-treated BMs progressed despite treatment (35\%). All cases of progression occurred in BMs in which $<80 \%$ ablation was achieved, whereas no disease progression was observed in BMs in which $\geq 80 \%$ ablation was achieved. Five BMs were treated with SLA, followed 1 month later by adjuvant SRS ( 5 Gy daily $\times 5$ days). No disease progression was observed in these patients despite ablation efficiency of $<80 \%$, suggesting that adjuvant hypofractionated SRS enhances the efficacy of SLA. Of the 23 SLA-treated patients, 3 suffered transient hemiparesis (13\%), 1 developed hydrocephalus requiring temporary ventricular drainage (4\%), and 1 patient who underwent SLA of a $28.9-\mathrm{cm}^{3}$ lesion suffered a neurological deficit requiring an emergency hemicraniectomy (4\%). Although there is significant heterogeneity in corticosteroid treatment post-SLA, most patients underwent a 2-week taper.

CONCLUSIONS Stereotactic laser ablation is an effective treatment option for BMs in which SRS fails. Ablation of $\geq$ $80 \%$ of BMs is associated with decreased risk of disease progression. The efficacy of SLA in this setting may be augmented by adjuvant hypofractionated SRS.

http://thejns.org/doi/abs/10.3171/2016.7.FOCUS16227

KEY WORDS brain metastases; stereotactic laser ablation; neurooncology; real-time MRI

A LTHOUGH the development of stereotactic radiosurgery (SRS) has fundamentally reshaped the treatment paradigm for brain metastases (BMs),, 16 there is an evolving recognition of its limitations. For tumor histological types that possess increased intrin- sic resistance to radiation, such as melanoma, treatment failure can be observed in $>25 \%$ of patients with BMs. ${ }^{6}$ For larger BMs or those adjacent to critical anatomical structures, delivery of radiation doses required for tumor control may incur neurological injury. ${ }^{8}$ Finally, as overall

ABBREVIATIONS BM = brain metastasis; $\mathrm{BNI}=$ Barrow Neurological Institute; $\mathrm{CC}=$ Cleveland Clinic; $\mathrm{CW}=$ Case Western; $\mathrm{QID}=4$ times daily; SLA = stereotactic laser ablation; SRS = stereotactic radiosurgery; TID = 3 times daily; UCSD = University of California San Diego.

SUBMITTED May 31, 2016. ACCEPTED July 27, 2016.

INCLUDE WHEN CITING DOI: 10.3171/2016.7.FOCUS16227.

* Mr. Ali and Ms. Carroll contributed equally to this work. Drs. Smith, Mohammadi, Sloan, and Chen share senior authorship of this work. 
survival improves for select patient populations, reports of BM progression after SRS-induced growth arrest are emerging. . $11,13^{2}$

Therapeutic options for BMs that recur after SRS remain limited. Repeat SRS is an option; ${ }^{19}$ however, it is associated with increased risk of radiation necrosis. ${ }^{5}$ Effective chemotherapeutic options in this setting remain elusive. ${ }^{3}$ It is in this context that stereotactic laser ablation (SLA) has been used. For SLA treatment of SRS-resistant metastases, a fiberoptic probe with laser-firing capacity is inserted into the cancerous tissue, where activation of the laser induces tissue destruction through thermocoagulation. ${ }^{4,9,17}$ Because clinical experiences with this technique remain limited, we present the pooled experience of 4 institutions where 26 BMs that recurred after SRS were treated with SLA.

\section{Methods}

\section{Patient Population and Data Collection}

The study was conducted under protocols approved by the institutional review boards at the following institutions: University of California San Diego (UCSD); Barrow Neurological Institute (BNI); Cleveland Clinic (CC); and Case Western (CW). Patient characteristics (age, sex, primary tumor histology, tumor location), corticosteroid regimens, and surgical morbidity information were collected through chart review. For BMs treated using the NeuroBlate system (Monteris Medical), tumor volume and percent of ablation covered by the blue isotherm line (tissue heated to $43^{\circ} \mathrm{C}$ for $\geq 10$ minutes) were calculated by the company software. Information pertaining to percent tumor ablation for lesions treated with the Visualase (Medtronic) system was not available. Tumor volumes for these lesions were calculated using 3D Slicer (www.slicer. org), ImageJ (https://imagej.nih.gov/ij/), or by estimation based on maximal diameters. Surveillance MRIs were performed every 1-2 months after SLA for all treated patients. Radiographic responses were assessed based on the Neurologic Assessment in Neuro-Oncology (NANO) criteria at the time of the last follow-up. ${ }^{12}$

\section{The SLA Procedures}

The SLA procedures were performed by the following authors: C.C.C.(UCSD); G.B. and A.M. (CC); K.S. (BNI); and A.S. (CW). Details of NeuroBlate and Visualase treatment have been reported elsewhere. ${ }^{2,15}$ All patients were treated with the NeuroBlate system, with the exceptions of the patients in Cases 12-14, who were treated using Visualase. All UCSD procedures were performed in a conventional MRI suite. Procedures at $\mathrm{CC}, \mathrm{BNI}$, and $\mathrm{CW}$ were done in intraoperative MRI suites.

\section{Adjuvant Hypofractionated SRS}

All patients treated at UCSD received postoperative hypofractionated SRS. Approximately 1 month after SLA, these patients underwent thin-cut MRI (1-mm cut) obtained with contrast (wherein images are obtained after systemic administration of contrast to better visualize blood vessel permeability) and CT scans obtained without contrast $(35-\mathrm{cm}$ field of view, $512 \times 512$ pixel size, 1.25 -
TABLE 1. Demographic and clinical characteristics in 23 patients with BMs after SRS

\begin{tabular}{|c|c|c|c|c|c|}
\hline $\begin{array}{l}\text { Case } \\
\text { No. }\end{array}$ & Age & Sex & Primary Tumor & $\begin{array}{l}\text { Location of } \\
\text { Metastasis }\end{array}$ & Institution \\
\hline 1 & 67 & $\mathrm{~F}$ & Colon & Lt thalamus & UCSD \\
\hline 2 & 58 & $\mathrm{~F}$ & Melanoma & Lt thalamus & UCSD \\
\hline 3 & 54 & $\mathrm{~F}$ & Breast & Rt thalamus & UCSD \\
\hline 4 & 60 & $F$ & Breast & Lt frontal & UCSD \\
\hline $4^{*}$ & & & & Lt parietal & UCSD \\
\hline 5 & 42 & $\mathrm{~F}$ & Breast & Lt frontal & CC \\
\hline $5^{*}$ & & & & Lt thalamus & $\mathrm{CC}$ \\
\hline 6 & 64 & $\mathrm{~F}$ & Bladder & Lt motor strip & $\mathrm{CC}$ \\
\hline 7 & 44 & $\mathrm{~F}$ & Breast & Rt insula & $\mathrm{CC}$ \\
\hline 8 & 48 & $\mathrm{~F}$ & Breast & Lt basal ganglia & $\mathrm{CC}$ \\
\hline 9 & 48 & $\mathrm{~F}$ & Breast & Lt basal ganglia & $\mathrm{CC}$ \\
\hline 10 & 42 & $\mathrm{~F}$ & Lung & Rt frontal & $\mathrm{CC}$ \\
\hline 11 & 74 & $\mathrm{~F}$ & Colon & Lt cerebellum & $\mathrm{CC}$ \\
\hline 12 & 73 & $M$ & Sarcoma & Rt parietal & $\mathrm{BNI}$ \\
\hline 13 & 58 & $M$ & Melanoma & Lt frontal & $\mathrm{BNI}$ \\
\hline 14 & 70 & $\mathrm{~F}$ & Ovarian & Lt parietal & $\mathrm{BNI}$ \\
\hline $14^{*}$ & & & & Lt occipital & $\mathrm{BNI}$ \\
\hline 15 & 77 & $F$ & Lung & Lt frontal & $\mathrm{BNI}$ \\
\hline 16 & 54 & $\mathrm{~F}$ & Lung & Lt frontal & CW \\
\hline 17 & 55 & $M$ & Lung & Lt thalamus & CW \\
\hline 18 & 58 & $\mathrm{~F}$ & Melanoma & Rt occipitoparietal & CW \\
\hline 19 & 45 & $\mathrm{~F}$ & Melanoma & Lt frontal & CW \\
\hline 20 & 74 & $M$ & Lung & Lt occipitoparietal & CW \\
\hline 21 & 64 & M & Melanoma & Lt frontal & CW \\
\hline 22 & 54 & M & Esophagus & Lt frontal & CW \\
\hline 23 & 77 & $M$ & Lung & Rt occiptal & $\mathrm{CW}$ \\
\hline
\end{tabular}

* In these patients 2 lesions were treated with SLA.

mm axial slice interval). Both MRI and CT studies were transferred to the treatment planning system, fused using a rigid autoregistration tool, and manually verified by the physicist and treating physicians. Planning was performed using Eclipse software, version 8.9 (Varian Medical Systems). The contrast-enhancing volume was contoured as clinical target volume by the treating neurosurgeon (C.C.C.) and radiation oncologist. The lesion was subsequently treated with SRS to the clinical target volume (5 Gy daily $\times 5$ days).

\section{Results}

\section{Patient and Tumor Characteristics}

There were 7 male and 16 female patients (Table 1). Two patients each underwent 2 SLAs for separate lesions in a single operation, and a third patient underwent 2 serial SLAs for discrete BMs. The mean age of the cohort was $59 \pm 11$ years. Histological findings in the BMs included the following: breast $(n=6)$; lung $(n=6)$; melanoma $(n=$ $5)$; colon $(n=2)$; ovarian $(n=1)$; bladder $(n=1)$; esophageal $(\mathrm{n}=1)$; and sarcoma $(\mathrm{n}=1)$. All BMs treated involved either the deep gray matter or eloquent cortex. 
TABLE 2. Treatment characteristics associated with SLA

\begin{tabular}{|c|c|c|c|c|c|c|}
\hline \multirow[b]{2}{*}{$\begin{array}{l}\text { Case } \\
\text { No. }\end{array}$} & \multicolumn{4}{|c|}{ Ablation Characteristics } & \multirow{2}{*}{$\begin{array}{l}\text { Radiographic } \\
\text { Response, per } \\
\text { RANO Criteria }\end{array}$} & \multirow[b]{2}{*}{ Surgical Morbidity \&/or New Deficits } \\
\hline & $\begin{array}{l}\text { Vol } \\
\left(\mathrm{cm}^{3}\right)\end{array}$ & $\begin{array}{c}\text { No. of } \\
\text { Trajectories }\end{array}$ & $\begin{array}{l}\% \text { Tumor Vol Covered } \\
\text { by Blue Isotherm Line }\end{array}$ & $\begin{array}{l}\text { Duration of } \\
\text { FU (days) }\end{array}$ & & \\
\hline 1 & 3.4 & 2 & 77.4 & 351 & PR & None \\
\hline 2 & 4.5 & 1 & 74.6 & 102 & PR & Hydrocephalus requiring ventricular drainage \\
\hline 3 & 5.5 & 1 & 98.2 & 252 & PR & None \\
\hline 4 & 3.2 & 1 & 92.4 & 138 & PR & None \\
\hline $4^{*}$ & 1.9 & 1 & 100 & 101 & PR & None \\
\hline 5 & 6.3 & 2 & 96.5 & 99 & SD & None \\
\hline $5^{*}$ & 5.3 & 1 & 63.0 & 94 & PD & Transient rt hemiparesis 4/5† \\
\hline 6 & 8.2 & 3 & 76.43 & 109 & PD & Transient rt hemiparesis $4 / 5 \dagger$ \\
\hline 7 & 16.9 & 3 & 86.45 & 64 & SD & None \\
\hline 8 & 3.5 & 1 & 97.86 & 146 & PR & None \\
\hline 9 & 28.9 & 1 & 99.28 & 83 & PR & Acute neurological deterioration requiring hemicraniectomy \\
\hline 10 & 2.7 & 1 & 100 & 170 & PR & None \\
\hline 11 & 2.6 & 1 & 100 & 145 & SD & None \\
\hline 12 & 2.3 & 1 & NA & 433 & PD & None \\
\hline 13 & 11.6 & 1 & NA & 77 & PD & None \\
\hline 14 & 10.1 & 1 & NA & 386 & PR & None \\
\hline $14^{*}$ & 0.4 & 1 & NA & 386 & PR & None \\
\hline 15 & 2.1 & 1 & 88.9 & 80 & PD & None \\
\hline 16 & 5.5 & 1 & 44.6 & 202 & PD & Transient rt hemiparesis $4 / 5 \dagger$ \\
\hline 17 & 12.1 & 1 & 73.6 & 652 & PR & None \\
\hline 18 & 4.1 & 1 & 86.2 & 338 & PD & None \\
\hline 19 & 3.7 & 1 & 69.3 & 795 & PR & None \\
\hline 20 & 9.6 & 1 & 67.8 & 124 & PD & None \\
\hline 21 & 11.2 & 1 & 88.3 & 323 & PR & None \\
\hline 22 & 13.1 & 1 & 70.1 & 91 & PD & None \\
\hline 23 & 4.4 & 1 & 88.6 & 76 & SD & None \\
\hline
\end{tabular}

$\mathrm{CR}=$ complete response $; \mathrm{FU}=$ follow-up; $\mathrm{NA}=$ not available; $\mathrm{PD}$ = progressive disease; $\mathrm{PR}$ = partial response; RANO = Radiologic Assessment in Neuro-Oncology; $\mathrm{SD}=$ stable disease

* In these patients 2 lesions were treated with SLA. Patients treated with Visualase and \% tumor treated were not calculated by the available software.

$\dagger$ Graded according to the MRC scale (Medical Research Council: Aids to examination of the peripheral nervous system. Memorandum no. 45. London: Her Majesty's Stationery Office, 1976).

\section{The SLA Parameters}

The median size of the lesion treated was $4.9 \mathrm{~cm}^{3}$ (range $\left.0.4-28.9 \mathrm{~cm}^{3}\right)$. The majority of the lesions were treated using single-trajectory SLA ( $\mathrm{n}=22$, or $85 \%)$. Two BMs required 2 trajectories $(8 \%)$, and 2 BMs required 3 trajectories $(8 \%)$. On average, $84 \%$ of the tumor was ablated using SLA (range $44.6 \%-100 \%$, Table 2). Complete ablation of the entire tumor volume, defined as $100 \%$ coverage of the tumor volume by the blue isotherm line, was achieved in only 3 of the 26 lesions (12\%).

\section{Radiographic Follow-Up}

All patients were followed with serial MRI studies for at least 2 months. The median follow-up was 141 days (range 64-794 days). Based on the Neurologic Assessment in Neuro-Oncology criteria, ${ }^{12}$ disease control was achieved in $17 \mathrm{BMs}$ (defined as stable disease [Fig. 1], or partial response [Fig. 2]). Nine BMs (35\%) showed disease progression after SLA. All instances of disease progres- sion occurred in lesions that underwent $<80 \%$ ablation. In contrast, no disease progression was observed in BMs in which $\geq 80 \%$ ablation was achieved (Table 2).

\section{Adjuvant Hypofractionated SRS Following SLA}

Five BMs were treated with SLA, followed by adjuvant SRS (5 Gy daily $\times 5$ days) 1 month later. The median follow-up time for these 5 BMs was 138 days (range 101-351 days), and no tumor growth was observed during followup. Twenty-one BMs were treated with SLA without subsequent SRS. With a median follow-up of 145 days, 9 of the 21 SLA-treated BMs showed radiographic evidence of tumor growth (43\%). The frequency of disease progression in BMs treated with SLA followed by hypofractionated SRS was significantly lower than that observed in BMs treated with SLA alone ( $p<0.05$, Student $t$-test). No evidence of radiation necrosis or progressive FLAIR signal abnormalities was observed in the patients treated with adjuvant, hypofractionated SRS following SLA. 

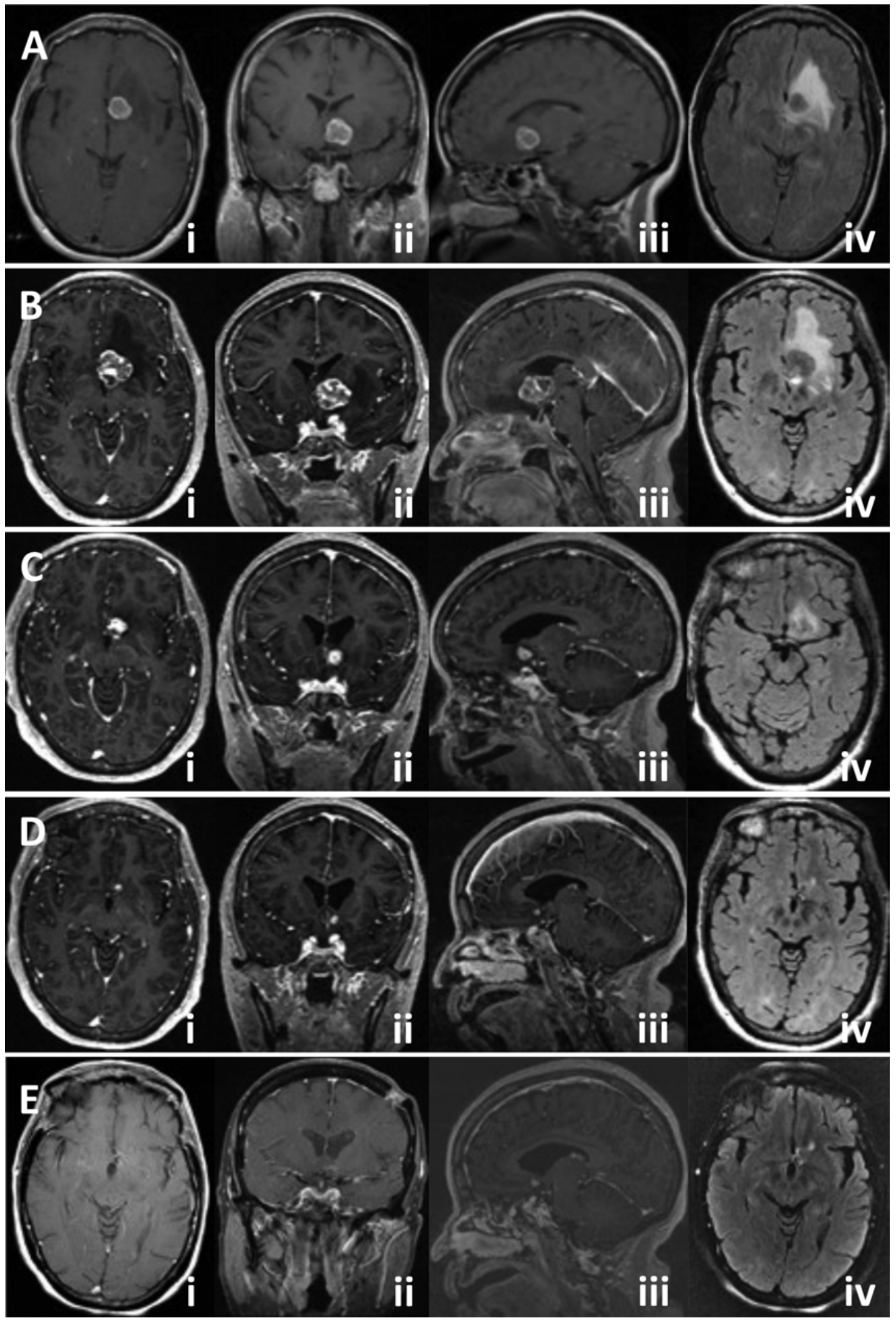

FIG. 1. MR images demonstrating stable BM disease control following SLA. A: Pretreatment axial (panel i), coronal (panel ii), and sagittal (panel iii) T1-weighted MR images obtained after administration of contrast and a FLAIR (panel iv) MR image of a deep left-sided BM. B-E: Axial (panel i), coronal (panel ii), and sagittal (panel iii) T1-weighted MR images obtained after administration of contrast, and a FLAIR (panel iv) MR image obtained 1 month (B), 3 months (C), 6 months (D), and 12 months (E) post-SLA, demonstrating no local recurrence. 

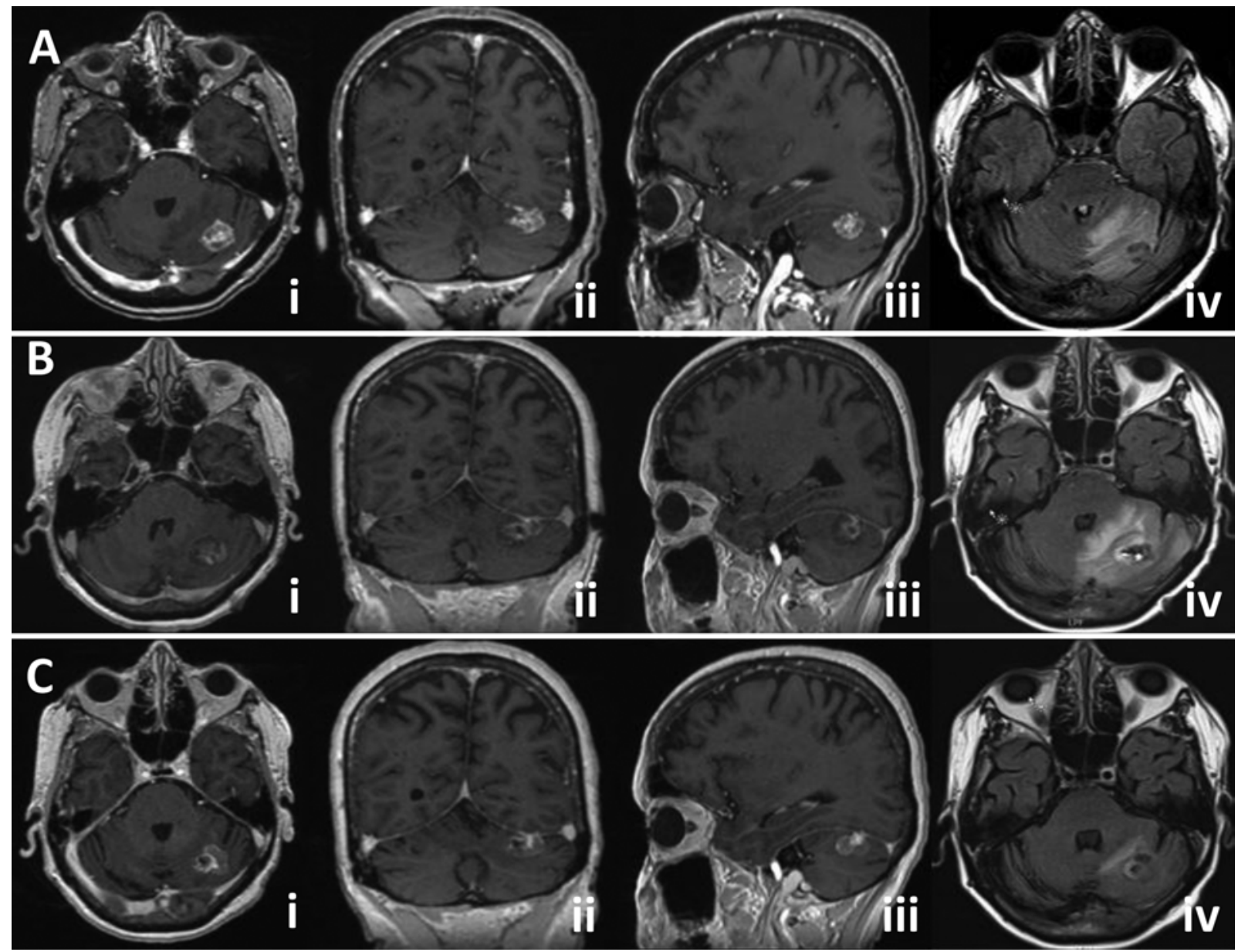

FIG. 2. MR images demonstrating partial treatment response of a BM following SLA. A: Pretreatment axial (panel i), coronal (panel ii), and sagittal (panel iii) T1-weighted MR images obtained after administration of contrast and a FLAIR (panel iv) MR image of a left-sided infratentorial BM. B and C: Axial (panel i), coronal (panel ii), and sagittal (panel iii) T1-weighted MR images obtained after administration of contrast, and a FLAIR (panel iv) MR image obtained 1 day (B) and 5 months (C) post-SLA, demonstrating a partial treatment response to SLA.

\section{Postoperative Corticosteroid Management}

There is significant heterogeneity in dexamethasone management after SLA (Table 3). The highest dose regimen in this case series was $10 \mathrm{mg}$ dexamethasone 4 times daily (QID) tapered over a span of 2 months. The most commonly used regimen was $4 \mathrm{mg}$ dexamethasone 3 times daily (TID) tapered over a span of 2 weeks. In 1 patient a pretreatment MRI revealed minimal peri-BM edema, and this patient tolerated SLA without postoperative dexamethasone treatment.

\section{Posttreatment Complications}

Of the 23 SLA-treated patients, 3 suffered transient hemiparesis (13\%) that recovered within 1 month of SLA; one of these patients underwent SLA for a BM located in the thalamus, another for a BM in the left frontal lobe, and the remaining patient underwent SLA for a BM located in the left motor strip. One patient with a left thalamic melanoma metastasis adjacent to the ventricle developed hydrocephalus after SLA, requiring temporary ventricular drainage $(4 \%)$. One patient with a $28.9-\mathrm{cm}^{3}$ lesion suffered malignant cerebral edema after SLA, requiring an emergency hemicraniectomy (4\%), and remained hemiplegic for the remainder of her life (83 days [Fig. 3]).

\section{Discussion}

In this report we provide radiographic follow-up for 26 BMs (in 23 patients) that recurred after SRS and were treated with SLA at 4 different institutions. The results indicate that SLA is an effective treatment option for BMs in which SRS fails. When $\geq 80 \%$ of the lesion is ablated, tumor control was uniformly observed. Consideration of the morbidities encountered in this series suggests that resection might be indicated instead of SLA for BMs previously treated with SRS that exceed $20 \mathrm{~cm}^{3}$ in volume. Additionally, careful monitoring of hydrocephalus after SLA for periventricular BMs is warranted. Transient or permanent neurological deficits may be expected after SLA of thalamic and motor-strip lesions.

Our study further suggests that when $<80 \%$ of a BM is ablated by SLA, the efficacy of disease control may be 
TABLE 3. Preoperative and postoperative steroid treatment regimens in patients who underwent SLA

\begin{tabular}{|c|c|c|}
\hline Case No. & $\begin{array}{l}\text { Preop Dexamethasone } \\
\text { Regimen }\end{array}$ & Postop Dexamethasone Regimen \\
\hline 1 & $4 \mathrm{mg}$ QID & $4 \mathrm{mg}$ TID $\times 4 \mathrm{~d} ; 3 \mathrm{mg}$ TID $\times 4 \mathrm{~d} ; 2 \mathrm{mg}$ TID $\times 4 \mathrm{~d} ; 1 \mathrm{mg}$ TID $\times 4 \mathrm{~d} ; \mathrm{DC}$ \\
\hline 2 & $4 \mathrm{mg}$ QID & $4 \mathrm{mg}$ TID $\times 4 \mathrm{~d} ; 3 \mathrm{mg}$ TID $\times 4 \mathrm{~d} ; 2 \mathrm{mg}$ TID $\times 4 \mathrm{~d} ; 1 \mathrm{mg}$ TID $\times 4 \mathrm{~d} ; \mathrm{DC}$ \\
\hline 3 & $4 \mathrm{mg}$ QID & $4 \mathrm{mg}$ TID $\times 4 \mathrm{~d} ; 3 \mathrm{mg}$ TID $\times 4$ d; $2 \mathrm{mg}$ TID $\times 4 \mathrm{~d} ; 1 \mathrm{mg}$ TID $\times 4 \mathrm{~d} ; \mathrm{DC}$ \\
\hline 4 & $4 \mathrm{mg}$ QID & $4 \mathrm{mg}$ TID $\times 1 \mathrm{~d} ; 3 \mathrm{mg}$ TID $\times 1 \mathrm{~d} ; 2 \mathrm{mg}$ TID $\times 1 \mathrm{~d} ; 1 \mathrm{mg}$ TID $\times 1 \mathrm{~d} ; \mathrm{DC}$ \\
\hline $4^{*}$ & & $4 \mathrm{mg}$ TID $\times 1 \mathrm{~d} ; 3 \mathrm{mg}$ TID $\times 1 \mathrm{~d} ; 2 \mathrm{mg}$ TID $\times 1 \mathrm{~d} ; 1 \mathrm{mg}$ TID $\times 1 \mathrm{~d} ; \mathrm{DC}$ \\
\hline 5 & $4 \mathrm{mg}$ QID & $4 \mathrm{mg}$ TID $\times 6 \mathrm{~d} ; 4 \mathrm{mg}$ OD \& $2 \mathrm{mg}$ BID $\times 6 \mathrm{~d} ; 2 \mathrm{mg}$ TID $\times 6 \mathrm{~d} ; 2 \mathrm{mg}$ BID until DC \\
\hline 6 & $2 \mathrm{mg} B \mathrm{BI}$ & $4 \mathrm{mg}$ TID $\times 6 \mathrm{~d} ; 2 \mathrm{mg}$ BID $\times 6 \mathrm{~d} ; 2 \mathrm{mg}$ TID $\times 6 \mathrm{~d} ; 2 \mathrm{mg} \mathrm{BID} \times 6 \mathrm{~d} ; \mathrm{DC}$ \\
\hline 7 & $4 \mathrm{mg} \mathrm{BID}$ & $4 \mathrm{mg} \mathrm{BID} \times 5 \mathrm{~d} ; 2 \mathrm{mg}$ TID $\times 5 \mathrm{~d} ; 2 \mathrm{mg} \mathrm{BID} \times 5 \mathrm{~d} ; \mathrm{DC}$ \\
\hline 8 & None & $\begin{array}{l}10 \mathrm{mg} \text { QID } \times 5 \mathrm{~d} ; 6 \mathrm{mg} \text { QID } \times 5 \mathrm{~d} ; 6 \mathrm{mg} \text { TID } \times 5 \mathrm{~d} ; 4 \mathrm{mg} \text { QID } \times 5 \mathrm{~d} ; 4 \mathrm{mg} \mathrm{TID} \times 5 \mathrm{~d} ; 4 \\
\mathrm{mg} \text { BID } \times 5 \mathrm{~d} ; 2 \mathrm{mg} \text { TID } \times 5 \mathrm{~d} ; 2 \mathrm{mg} \mathrm{BID} \times 20 \mathrm{~d} ; \mathrm{DC}\end{array}$ \\
\hline 9 & $4 \mathrm{mg} \mathrm{BID}$ & $\begin{array}{l}10 \mathrm{mg} \text { QID } \times 5 \mathrm{~d} ; 6 \mathrm{mg} \text { QID } \times 5 \mathrm{~d} ; 6 \mathrm{mg} \text { TID } \times 5 \mathrm{~d} ; 4 \mathrm{mg} \text { QID } \times 5 \mathrm{~d} ; 4 \mathrm{mg} \mathrm{TID} \times 5 \mathrm{~d} ; 4 \\
\mathrm{mg} \text { BID } \times 5 \mathrm{~d} ; 2 \mathrm{mg} \text { TID } \times 5 \mathrm{~d} ; 2 \mathrm{mg} \text { BID } \times 20 \mathrm{~d} ; \mathrm{DC}\end{array}$ \\
\hline 10 & $4 \mathrm{mg} \mathrm{BID}$ & $4 \mathrm{mg}$ QID $\times 3 \mathrm{~d} ; 4 \mathrm{mg}$ TID $\times 4 \mathrm{~d} ; 2 \mathrm{mg}$ TID $\times 7 \mathrm{~d} ; 1 \mathrm{mg} \mathrm{BID} \times 7 \mathrm{~d} ; \mathrm{DC}$ \\
\hline 11 & None & $4 \mathrm{mg}$ TID $\times 5 \mathrm{~d} ; 4 \mathrm{mg} \mathrm{BID} \times 5 \mathrm{~d} ; 2 \mathrm{mg}$ TID $\times 4 \mathrm{~d} ; 2 \mathrm{mg} \mathrm{BID} \times 4 \mathrm{~d} ; \mathrm{DC}$ \\
\hline 12 & None & None \\
\hline 13 & $4 \mathrm{mg} \mathrm{BID}$ & $4 \mathrm{mg}$ QID $\times 2 \mathrm{~d} ; 4 \mathrm{mg}$ TID $\times 4 \mathrm{~d} ; 2 \mathrm{mg}$ BID $\times 4 \mathrm{~d} ; 2 \mathrm{mg}$ QD $\times 2 \mathrm{~d} ; \mathrm{DC}$ \\
\hline 14 & $4 \mathrm{mg} \mathrm{BID}$ & $4 \mathrm{mg} \mathrm{BID} \times 3 \mathrm{~d} ; 2 \mathrm{mg}$ BID $\times 3 \mathrm{~d} ; 2 \mathrm{mg} \mathrm{QD} \times 3 \mathrm{~d} ; \mathrm{DC}$ \\
\hline 15 & $4 \mathrm{mg} \mathrm{BID}$ & $4 \mathrm{mg} \mathrm{BID} \times 3 \mathrm{~d} ; 2 \mathrm{mg} \mathrm{BID} \times 3 \mathrm{~d} ; 2 \mathrm{mg} \mathrm{QD} \times 3 \mathrm{~d} ; \mathrm{DC}$ \\
\hline 16 & $4 \mathrm{mg} \mathrm{BID}$ & $10 \mathrm{mg}$ QID $\times 3 \mathrm{~d} ; 6 \mathrm{mg}$ TID $\times 3 \mathrm{~d} ; 4 \mathrm{~g} \mathrm{BID} \times 3 \mathrm{~d} ; 2 \mathrm{mg}$ BID until postop visit in 2-3 wks \\
\hline 17 & $4 \mathrm{mg} \mathrm{BID}$ & $10 \mathrm{mg}$ QID $\times 3 \mathrm{~d} ; 6 \mathrm{mg}$ TID $\times 3 \mathrm{~d} ; 4 \mathrm{~g}$ BID $\times 3 \mathrm{~d} ; 2 \mathrm{mg}$ BID until postop visit in 2-3 wks \\
\hline 18 & $4 \mathrm{mg} \mathrm{BID}$ & $10 \mathrm{mg}$ QID $\times 3 \mathrm{~d} ; 6 \mathrm{mg}$ TID $\times 3 \mathrm{~d} ; 4 \mathrm{~g}$ BID $\times 3 \mathrm{~d} ; 2 \mathrm{mg}$ BID until postop visit in 2-3 wks \\
\hline 19 & $4 \mathrm{mg} \mathrm{BID}$ & $10 \mathrm{mg}$ QID $\times 3 \mathrm{~d} ; 6 \mathrm{mg}$ TID $\times 3 \mathrm{~d} ; 4 \mathrm{~g}$ BID $\times 3 \mathrm{~d} ; 2 \mathrm{mg}$ BID until postop visit in 2-3 wks \\
\hline 20 & $4 \mathrm{mg} \mathrm{BID}$ & $10 \mathrm{mg}$ QID $\times 3 \mathrm{~d} ; 6 \mathrm{mg}$ TID $\times 3 \mathrm{~d} ; 4 \mathrm{~g}$ BID $\times 3 \mathrm{~d} ; 2 \mathrm{mg}$ BID until postop visit in 2-3 wks \\
\hline 21 & $4 \mathrm{mg} \mathrm{BID}$ & $10 \mathrm{mg}$ QID $\times 3 \mathrm{~d} ; 6 \mathrm{mg}$ TID $\times 3 \mathrm{~d} ; 4 \mathrm{~g} \mathrm{BID} \times 3 \mathrm{~d} ; 2 \mathrm{mg}$ BID until postop visit in 2-3 wks \\
\hline 22 & $4 \mathrm{mg} \mathrm{BID}$ & $10 \mathrm{mg}$ QID $\times 3 \mathrm{~d} ; 6 \mathrm{mg}$ TID $\times 3 \mathrm{~d} ; 4 \mathrm{~g}$ BID $\times 3 \mathrm{~d} ; 2 \mathrm{mg}$ BID until postop visit in 2-3 wks \\
\hline 23 & $4 \mathrm{mg} \mathrm{BID}$ & $10 \mathrm{mg}$ QID $\times 3 \mathrm{~d} ; 6 \mathrm{mg}$ TID $\times 3 \mathrm{~d} ; 4 \mathrm{~g} \mathrm{BID} \times 3 \mathrm{~d} ; 2 \mathrm{mg}$ BID until postop visit in 2-3 wks \\
\hline
\end{tabular}

augmented by adjuvant hypofractionated SRS (5 Gy daily $\times 5$ days). Because SLA is typically preferred when the location of a BM involves regions of deep gray matter or eloquent cortex, incomplete ablation may be necessary to minimize the risk of neurological deficits. Our results indicate that hypofractionated SRS may augment the local control of these incompletely ablated tumors. Although the risk of radiation necrosis related to repeat SRS is a consideration, ${ }^{5}$ it is likely to be mitigated by SLA ablation of the tumor mass..$^{10,18}$ Supporting this hypothesis, we did not observe radiographic evidence of radiation necrosis in patients treated with adjuvant, hypofractionated SRS following SLA. Nevertheless, the number of patients treated with combined SRS and hypofractionated SRS was limited. Validation of these results in future studies is warranted.

Temporary increases in cerebral edema after SLA is a well-described phenomenon..$^{14}$ For this reason, most of the patients in this series were treated with corticosteroids after SLA. Although there are significant differences in surgeon preference regarding corticosteroid management, the most common regimen involved $4 \mathrm{mg}$ dexamethasone TID tapered over a 2-week period. In cases in which the treating surgeon was concerned about the risk of malignant edema, $10 \mathrm{mg}$ dexamethasone QID tapered over a 2-month period was used. Given that 1 patient tolerated SLA-related edema without postprocedure corticosteroids, this treatment may not be necessary in select patients with minimal peri-BM edema.

The findings reported here are subject to all limitations inherent to case series in which there are a small number of patients and heterogeneous clinical practices. Admittedly, most patients in this series were followed for a limited duration, but this follow-up (median 141 days) must be taken in the context of the poor survival expectation of patients with Stage IV cancer with BMs in which SRS has failed.? That said, assessment of radiation necrosis in patients who underwent adjuvant, hypofractionated SRS after SLA will require longer follow-up than that carried out in this study. Despite these limitations, we believe that our results offer pilot data for guiding future studies of SLA as a treatment for BMs in which SRS has failed.

\section{Conclusions}

Stereotactic laser ablation is an effective treatment option for patients suffering BM recurrence after SRS. Ablation of $\geq 80 \%$ of $\mathrm{BMs}$ is desirable to minimize risk of dis- 

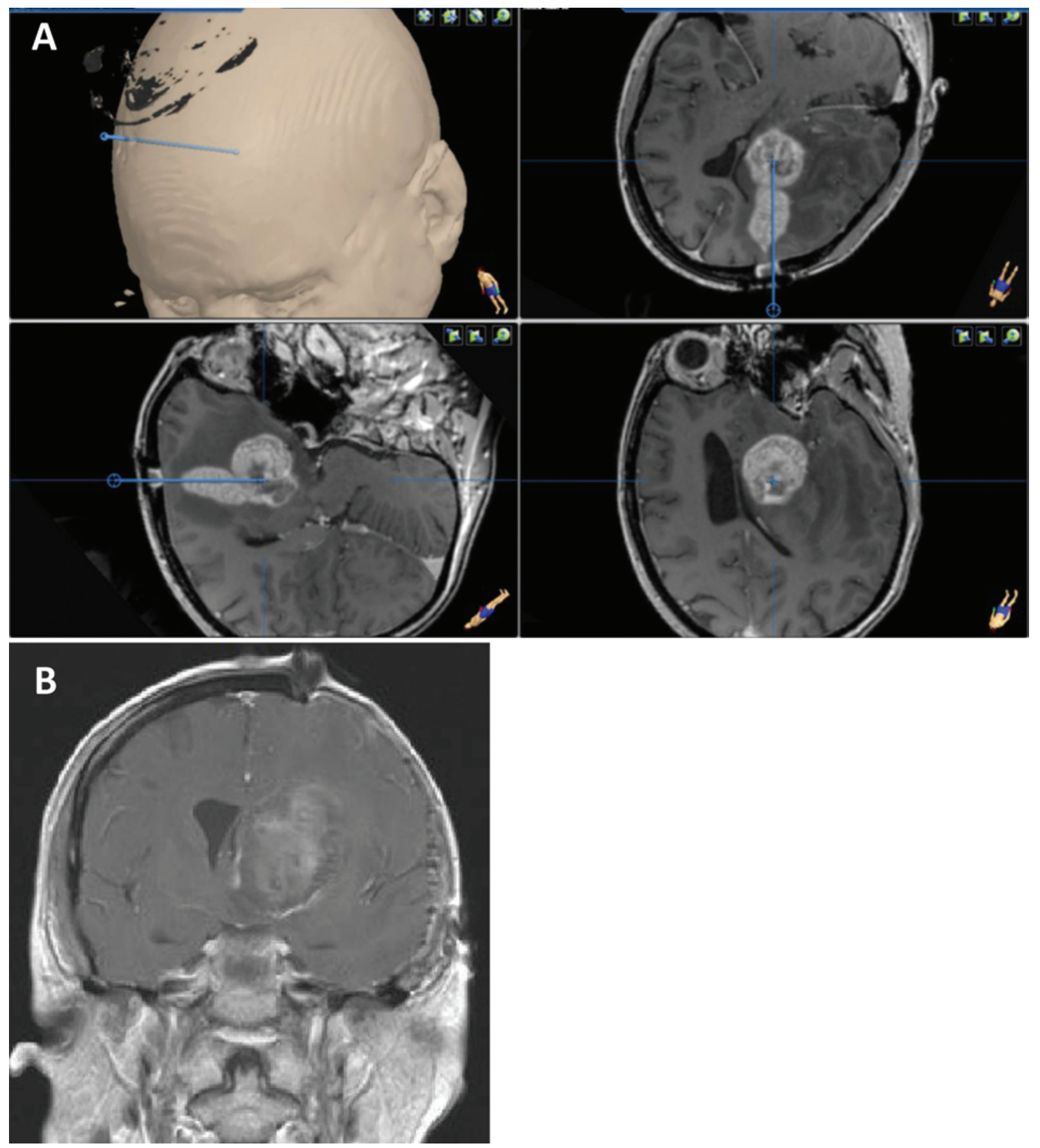

FIG. 3. Malignant cerebral edema following SLA for a large BM. A: The SLA trajectory for a $28.9-\mathrm{cm}^{3}$ thalamic BM. B: Coronal T1weighted MR image obtained after administration of contrast following hemicraniectomy for symptomatic cerebral edema post-SLA.

ease progression. The efficacy of SLA may be augmented by adjuvant hypofractionated SRS.

\section{References}

1. Aoyama H, Shirato H, Tago M, Nakagawa K, Toyoda T, Hatano K, et al: Stereotactic radiosurgery plus whole-brain radiation therapy vs stereotactic radiosurgery alone for treatment of brain metastases: a randomized controlled trial. JAMA 295:2483-2491, 2006

2. Carpentier A, McNichols RJ, Stafford RJ, Itzcovitz J, Gui- chard JP, Reizine D, et al: Real-time magnetic resonanceguided laser thermal therapy for focal metastatic brain tumors. Neurosurgery 63 (1 Suppl 1):ONS21-ONS29, 2008

3. Grimm SA: Treatment of brain metastases: chemotherapy. Curr Oncol Rep 14:85-90, 2012

4. Hawasli AH, Kim AH, Dunn GP, Tran DD, Leuthardt EC: Stereotactic laser ablation of high-grade gliomas. Neurosurg Focus 37(6):E1, 2014

5. Kwon KY, Kong DS, Lee JI, Nam DH, Park K, Kim JH: Outcome of repeated radiosurgery for recurrent metastatic brain tumors. Clin Neurol Neurosurg 109:132-137, 2007 
6. Liew DN, Kano H, Kondziolka D, Mathieu D, Niranjan A, Flickinger JC, et al: Outcome predictors of Gamma Knife surgery for melanoma brain metastases. Clinical article. J Neurosurg 114:769-779, 2011

7. Marshall DC, Marcus LP, Kim TE, McCutcheon BA, Goetsch SJ, Koiso T, et al: Management patterns of patients with cerebral metastases who underwent multiple stereotactic radiosurgeries. J Neurooncol 128:119-128, 2016

8. Minniti G, Clarke E, Lanzetta G, Osti MF, Trasimeni G, Bozzao A, et al: Stereotactic radiosurgery for brain metastases: analysis of outcome and risk of brain radionecrosis. Radiat Oncol 6:48, 2011

9. Mohammadi AM, Hawasli AH, Rodriguez A, Schroeder JL, Laxton AW, Elson P, et al: The role of laser interstitial thermal therapy in enhancing progression-free survival of difficult-to-access high-grade gliomas: a multicenter study. Cancer Med 3:971-979, 2014

10. Rahmathulla G, Recinos PF, Valerio JE, Chao S, Barnett GH: Laser interstitial thermal therapy for focal cerebral radiation necrosis: a case report and literature review. Stereotact Funct Neurosurg 90:192-200, 2012

11. Rava P, Sioshansi S, DiPetrillo T, Cosgrove R, Melhus C, Wu $\mathrm{J}$, et al: Local recurrence and survival following stereotactic radiosurgery for brain metastases from small cell lung cancer. Pract Radiat Oncol 5:e37-e44, 2015

12. Reardon DA, Nayak L, DeAngelis LM, Wen PY, Brandes AA, Soffietti R, et al: The Neurologic Assessment in NeuroOncology (NANO) Scale: A tool to assess neurologic function for integration in the radiologic assessment in neurooncology (RANO) criteria. Neuro Oncol 16 (Suppl 2):ii76, 2014 (Abstract P15.13)

13. Regine WF, Huhn JL, Patchell RA, St Clair WH, Strottmann J, Meigooni A, et al: Risk of symptomatic brain tumor recurrence and neurologic deficit after radiosurgery alone in patients with newly diagnosed brain metastases: results and implications. Int J Radiat Oncol Biol Phys 52:333-338, 2002

14. Schwabe B, Kahn T, Harth T, Ulrich F, Schwarzmaier HJ: Laser-induced thermal lesions in the human brain: short- and long-term appearance on MRI. J Comput Assist Tomogr 21:818-825, 1997

15. Sloan AE, Ahluwalia MS, Valerio-Pascua J, Manjila S, Torchia MG, Jones SE, et al: Results of the NeuroBlate System first-in-humans Phase I clinical trial for recurrent glioblastoma: clinical article. J Neurosurg 118:1202-1219, 2013

16. Soliman H, Das S, Larson DA, Sahgal A: Stereotactic radiosurgery (SRS) in the modern management of patients with brain metastases. Oncotarget 7:12318-12330, 2016

17. Sugiyama K, Sakai T, Fujishima I, Ryu H, Uemura K, Yokoyama T: Stereotactic interstitial laser-hyperthermia using Nd-YAG laser. Stereotact Funct Neurosurg 54-55:501-505, 1990

18. Torres-Reveron J, Tomasiewicz HC, Shetty A, Amankulor NM, Chiang VL: Stereotactic laser induced thermotherapy (LITT): a novel treatment for brain lesions regrowing after radiosurgery. J Neurooncol 113:495-503, 2013

19. Yomo S, Hayashi M: Salvage stereotactic radiosurgery with adjuvant use of bevacizumab for heavily treated recurrent brain metastases: a preliminary report. J Neurooncol 127:119-126, 2016

\section{Disclosures}

Dr. Chen is a consultant for Monteris Medical and has consulted for MRI Interventions. Drs. Mohammadi and Sloan are consultants for Monteris Medical, Inc. Dr. Smith is a consultant for Monteris Medical, Inc.; Medtronic, Inc.; and OsteoMed.

\section{Author Contributions}

Conception and design: Chen. Acquisition of data: Chen, Hamelin, Chang, Lemkuil, Sharma, Barnholtz-Sloan, Myers, Barnett, Smith, Mohammadi, Sloan. Analysis and interpretation of data: Chen, Ali, Carroll, Rennert, Hamelin, Chang, Lemkuil, Sharma, Barnholtz-Sloan, Myers, Barnett, Smith, Mohammadi. Drafting the article: Chen, Ali, Carroll, Rennert, Sloan. Critically revising the article: Chen, Ali, Carroll, Rennert, Sharma, Barnholtz-Sloan, Barnett, Smith, Mohammadi, Sloan. Reviewed submitted version of manuscript: all authors. Approved the final version of the manuscript on behalf of all authors: Chen.

\section{Correspondence}

Clark C. Chen, Department of Neurosurgery, University of California, San Diego, 3855 Health Sciences Dr. \#0987, La Jolla, CA 92093.email: clarkchen@ucsd.edu. 